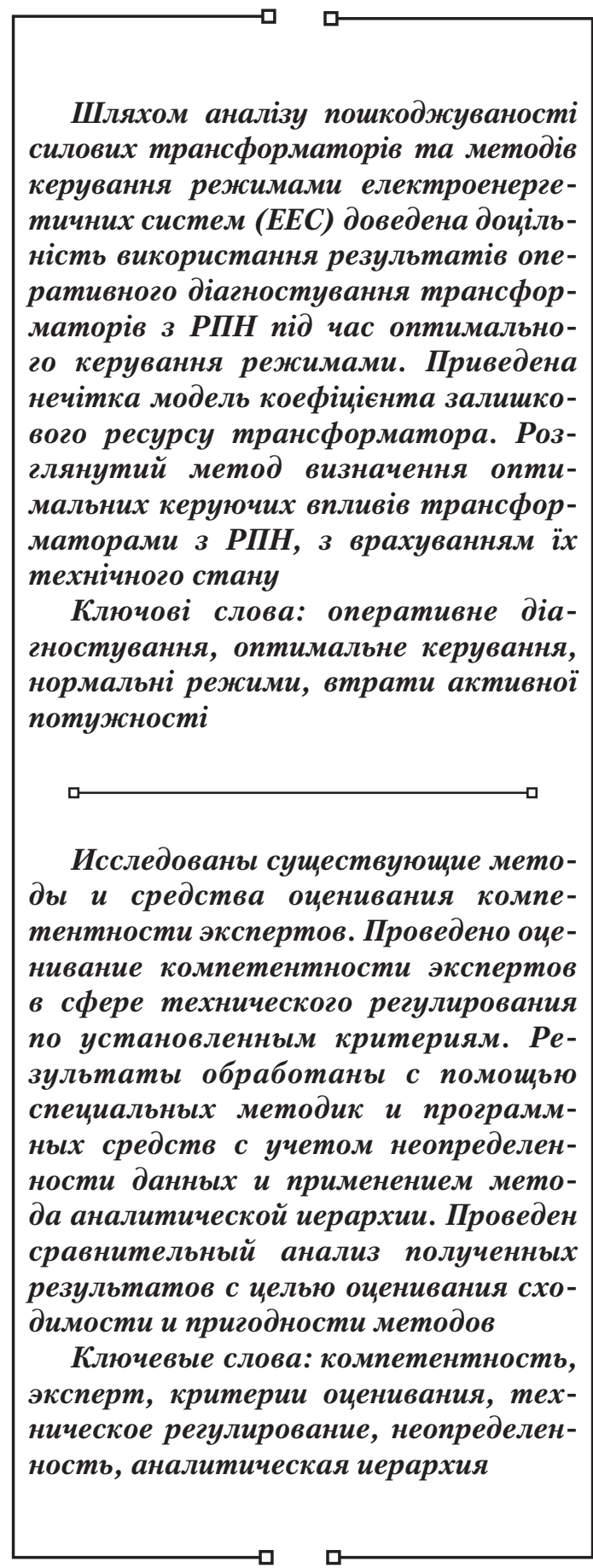

UDC 621.311: 621.314

DOI: $10.15587 / 1729-4061.2017 .108945$

\section{DETERMINATION OF OPTIMAL TRANSFORMATION RATIOS OF POWER SYSTEM TRANSFORMERS IN CONDITIONS OF INCOMPLETE INFORMATION REGARDING THE VALUES OF DIAGNOSTIC PARAMETERS}

O. R u b a ne n ko $\mathrm{PhD}$, Associate Professor* E-mail: rubanenkoae@ukr.net

O. Kaz m i r u k $\mathrm{PhD}$, Assistant* E-mail: oleg_kazmiruk@hotmail.com V. B a nd u r a $\mathrm{PhD}$, Associate Professor** E-mail: bandura_3@ukr.net

V. Mat vi j c h u k Doctor of Technical Sciences*** E-mail: olenarubanenko@ukr.net O. R u b a n e n k o $\mathrm{PhD} * \star \star$

E-mail: olenarubanenko@ukr.net *Department of Electric Stations and Systems Vinnytsia National Technical University Khmelnytske highway, 95, Vinnytsia, Ukraine, 21021 **Department of Processes and equipment processing and food production named after Prof. P. S. Bernik**** $\star * *$ Department of Electrical Engineering Systems, Technologies and Automation in Agroindustrial Complex $* * \star *$ $\star \star * \star V i n n y t s i a$ National Agrarian University Soniachna str., 3, Vinnitsa, Ukraine, 21008

\section{Introduction}

A characteristic feature of the present day situation is the attempts of utility companies to increase energy efficiency in conditions of continuing aging of high voltage equipment.

The practice of large-scale introduction of the intelligent support of decision making of optimal solution processes proves their efficiency. One of the directions of efficiency increase of electric energy transportation is improvement of methods and means of active power losses reduction on conditions of maintaining reliable operation of high voltage equipment, including out-dated equipment.
The set of electric energy system (EES) states and the processes of transition from one state into another is the EES mode (further-mode), characterized by the parameters, for instance, electrical: substations voltages and loads, currents in transmission lines, transformation ratios of the transformers, etc. Normal operation mode of EES modes. Control by the system of on-line dispatching control (LDC). Modern LDS technologies, for instance, provided by Smart Grids concept, are aimed at improvement of its information support. This enables to implement more efficiently energy saving technologies in electric energy systems, when out of date high-voltage equipment is used. 


\section{Literature review and problem statement}

In [1], the technique of voltage drop decrease in separate parts of distribution electric grids is suggested, but it does not take into account the technical state of regulating devices [1]. In [2], on the example of Indian electric grids, the statistics of the increase of power, transmitted in electric grid is considered. It is proved that such an increase leads to the overload of some power lines, to the rapid aging of high-voltage equipment, to the unwanted rapid decrease in the remaining equipment life, to the failure of equipment. As a result, the duration and cost of repairing damaged equipment increases and power losses increase in the branches of the circuit of electrical systems, which at the time of repair work in non-optimal modes. It is stated that in order to improve the grid reliability and efficiency of energy transmission, it is necessary to use power transformers, equipped with LTC and automatic or automated control systems for such LTC control. It enables to control power flows in EES by means of LTC so that the parameters of electric grids modes were with in the limits of normal optimal values of equipment (transmission lines, switching devices, transformers, etc.) parameters.

This is provided by usage of FACTS technologies. For instance, in [3], the possibilities of using a phase-shift transformer for power flows change in the electric energy system to reduce power losses in the process of energy transmission in transmission lines of the Slovak Republic are considered. In [4], the high price of FACTs technologies usage in the energy branch for the reduction of electrical power losses is proved. In [5], three variants of power flows control in the electric grid, using three FACTs devices are consider with Thyristor Controlled Series Capacitor (TCSC), Static Synchronous Series Compensator (SSSC) and phase-shift transformer (PST), but in [3-5] no attention is paid to the state of equipment, used for modes control. In [6], the conclusion is made that prolongation of power transformers operation term for 20-30 years is more profitable than their replacement by new ones, and the number of power transformers in the USA, that have been in operation for more than 25 years (certificate resource - 25 years) is approximately $65 \%$.

That is why, computer systems performers for on-line monitoring of the high-voltage equipment and its elements state are used [7].

The example of such systems could be monitoring systems KIN-750 or KIV-500, these systems enable to control insulation of high-voltage equipment and its elements high-voltage bushings of power transformers in the process of their operation.

As it is noted in [8], monitoring of high-voltage equipment provides realization

of the observation over the values of diagnostic parameters and determining the current technical state of that equipment

In [9], it is stated that the main technical characteristics and indices of modern means of monitoring the regimes allow improving the reliability of the systems of on-line control of the unified energy system of Ukraine. This is possible as a result of new possibilities for the solution of supervision control problems. These possibilities emerge as a result of introduction of such means. The results of the power trans- former technical state determination can be used in order to determine current loading capacity [10].

In [11], it is proved that application of new technologies, methods and control facilities, allows reducing active power losses in electric grids. Account of the current technical state of power transformers with regulation devices under voltage decreases the risk of damage in the process of modes control [12].

In [13], attention is paid to the system of continuous monitoring of the technical state of power transformers, the given system is used in the transformers of joint-stock company "Magnitogorsk Metallurgical Complex", HYDRAN analyzer, methods of localization and identification of faults, practical necessity of partial discharge control is underlined, but the results of diagnostics during optimal modes control are not paid attention to.

In [14], it is noted that in local electric systems, in order to provide stable operation and indices of electric energy quality, it is necessary to use modern control systems that take into consideration voltages in nodes and frequency and eliminate emergency deviations. At the same time, in [15], attention is paid to the modeling of no-stationary critical operation modes of EES in the process of parameters change in wide limits by means of application of non-linear mathematical models. This enables to study the consequences of such modes, promptly take measures, aimed at their prevention or optimal elimination. In the papers [14, 15], the technical state of the equipment of these systems is not taken into account, this can lead to the damage of the equipment and undersupply of energy to the consumers.

Thus, the problem of development of the methods of diagnostics results account during optimal control of EES modes is not solved.

It is known that real-time operation control (RTOC) in Ukraine is carried by a man. Overloading of this person with a great volume of diagnostic parameters data, especially in conditions of limited time for decision-making, leads to non-optimal actions. In the process of modes on-line control, especially post-accident modes, it is expedient to assess the state of equipment by generalized indices, for instance, by residual resources coefficient of the transformers (RRCT). The development of the method of on-line diagnostics of the transformers and the account of RRCT in the process of ESS modes control for minimization of total losses of active power are not considered in literature sources and are the subject of the authors' study.

\section{The aim and objectives of the study}

The aim of the research is the development of the method of real-time diagnostics of the transformers with LTC and account of PRCT values in the process of EES modes control for minimization of active power losses. To achieve this aim, the following objectives are to be solved:

- to substantiate the expediency of applying the results of real-time diagnostics of LTC-transformers in the process of optimal control of EES modes;

- to develop a fuzzy model of the residual resource coefficient of the transformers (RRCT);

- to develop the method of RRCT values and power transformers with LTC state account in the process of EES modes optimal control. 


\section{Materials and methods of transformers} diagnostic study

Automation of the process of power flow control may be provided by means of centralized remotely controlled alternative usage of switching devices (LTC) of the transformers. Under such conditions, there appears the possibility of the analysis of control actions of separate LTC on mode parameters of EES by means of the feedback. This approach improves the operation quality of adaptive control automatic systems of the LTC position control. For this purpose, at considerable changes of the load schedule, it is necessary to perform ranking of the transformers with LTC by the quality of their impact on maintaining optimal parameters of the modes.

Realization of measures, aimed at reduction of power losses is limited by the possibilities of the equipment involved in the provision of optimal mode; namely, by its technical state. It is known that the damage of high voltage equipment during mode control (for instance, power transformers) leads to losses that considerably exceed the cost of electric energy, saved as a result of losses decrease. The failure rate of the out=dated high voltage equipment (power transformers, shunting reactors, instrument current and voltage transformers, switches, etc.) increases, when such equipment has been in operation for more than 25 years [16]. Taking into consideration the fact that the control of EES modes is accompanied by the operation of switching devices, regulation devices of transformers, emergence of switching surges, ferro- resonances, currents increase in power and instrument transformers, transmission lines, etc., the control of modes must be realized, taking into consideration their technical state [3, 4] and possible expenses for their replacement or repair.

Thus, it is necessary to know the current state of high voltage electric equipment of EES-that is in operation during modes control.

\section{Determination of current technical state of power transformers}

We will consider the method of determination of power transformers current state and RRCT values in the process of EES modes optimal control on the example of power high voltage transformers that have on-load-tap changing device.

We propose to evaluate the technical state of a power transformer by means of the analysis of the value of its residual resource coefficient. The power transformer residual resource coefficient has the dimensionality in relative units and can change in the process of operation in the range from one (the best technical state) to zero (the worst technical state, when the transformer must be removed out of service for inspection, repair, replacement, etc.). Then, we will consider the example of residual resource coefficient determination of the transformer ATDCTN 125000-330/110. First, we will study the statistics of the failure rate of such transformers. Table 1 contains the example of possible reasons and amount of transformers removal out of service that is close to the data, published in [16, 17].

Table 1 shows that the transformers are often removed out of service due to humidification and contamination of oil and insulation, as well as high-voltage inputs defects.
Table 1

Reasons of removing out of service power transformers

\begin{tabular}{|c|c|c|c|c|}
\hline $\begin{array}{l}\text { Transform- } \\
\text { er element }\end{array}$ & $\begin{array}{l}\text { Designa- } \\
\text { tion }\end{array}$ & Parameter name & Units & $\%$ \\
\hline \multirow{3}{*}{ Windings } & $Z_{k}$ & Winding deformation & 8 & 1.6 \\
\hline & $t^{0}$ & $\begin{array}{l}\text { Deterioration of con- } \\
\text { tact joints state }\end{array}$ & 10 & 2 \\
\hline & $P_{i . p}$ & $\begin{array}{l}\text { Idle power that } \\
\text { characterizes of the } \\
\text { magnetic quality }\end{array}$ & 15 & 3 \\
\hline \multirow{2}{*}{ Insulation } & $R_{\text {in }}$ & $\begin{array}{c}\text { Contamination of } \\
\text { isolation }\end{array}$ & 65 & 13.4 \\
\hline & $W$ & $\begin{array}{l}\text { Humidification of the } \\
\text { isolation }\end{array}$ & 48 & 10 \\
\hline Bushings & $k_{\text {bush }}$ & Defects of bushings & 74 & 15.2 \\
\hline \multirow{3}{*}{ Oil } & $C A D G_{c}$ & $\begin{array}{l}\text { Content of dissolved } \\
\text { gases }\end{array}$ & 71 & 14.6 \\
\hline & $P C A$ & $\begin{array}{l}\text { High moisture content } \\
\text { and deviations of other } \\
\text { parameters of the oil }\end{array}$ & 43 & 9 \\
\hline & $C A D G_{d}$ & Discharges in oil & 64 & 13.2 \\
\hline LTC & $k_{\text {def.LTC }}$ & LTC defects & 45 & 9.3 \\
\hline \multirow{2}{*}{$\begin{array}{l}\text { Cooling } \\
\text { system }\end{array}$} & $I_{m o t o r}$ or $I_{m t}$ & $\begin{array}{l}\text { The current of oil } \\
\text { pump drive motor }\end{array}$ & 14 & 2.9 \\
\hline & $t_{\text {cool }}^{o}$ & Coolers temperature & 16 & 3.3 \\
\hline Tank & $k_{\text {tank }}$ & Tank leakage & 12 & 2.5 \\
\hline \multicolumn{3}{|c|}{ Total } & 485 & 100 \\
\hline
\end{tabular}

In Table 1, such symbols are used: $Z_{k}$ is the resistance of the transformer windings (during measurements in short - circuit mode); $t^{\circ}$ is the temperature of contact points (for instance, bushing of the bus duct or with winding lead); $P_{i . p}$. idle mode power that characterizes the quality of magnetic circuit; $R_{i n}$ is the resistance of the insulation for revealing the contamination and aging of solid and liquid insulation (also it is necessary to determine the capacity and dielectric loss tangent, also it is desirable to determine the degree of polymerization); $W$ - humidification of the isolation; $k_{\text {resid.res.bush }}$ or $k_{b u s h}$ is the residual resource coefficient of the bushings; $C A D G_{C}$ is the residual resource coefficient of the transformer by the results of chromatographic analysis of dissolved gas in the transformer oil of the tank and LTC (ethylene, ethane, methane) of the transformer that characterizes oil contamination by the gases, dissolved in it and among them acetylene and hydrogen (for revealing of discharges); $P C A$ is the residual resource coefficient of the transformer by the results of physical-chemical analyses of transformer oil from transformer tank, contactor and LTC tap changer; $C A D G_{d}$ is the residual resource coefficient of the transformer by the results of chromatographic analysis of the dissolved hydrogen and acetylene in the transformer oil of the tank and LTC of the transformer tap changer in order to reveal the discharge; $k_{\text {def.LTC }}$ or $k_{\text {LTC }}$ is the coefficient of the transformer LTC residual resource; $I_{m}$ is the current of electric motors oil pumps and fans of cooling system; $t_{\text {cool }}$ is the coolers temperature; $k_{\text {tank }}$ is the residual resource 
coefficient of the transformer tank, determined by the availability (takes the value "0") or absence of oil leakage (takes the value 1).

The task of creating a mathematical model is complicated with incomplete initial data, when some parameters are known at the time of calculations, for example, because of the need for additional studies. To establish mutual relationships of diagnostic parameters, the technology of fuzzy simulation is very constructive. This simulation allows obtaining more reliable results compared to the results of existing diagnostic systems.

In Table 1, under the term the controlled diagnostic parameter we mean the parameter, deviation of which from the norm helped to remove the transformer out of service or was taken into account in the process of its removal out of service. In Table 1, the following diagnostic parameters are given: parameters; that characterize the state of the windings, insulation, bushings, oil, LTC, cooling systems, tank.

Having analyzed the data of Table 1, the scheme was created that shows whether the impact of diagnostic parameters on the coefficient of total residual resource of the transformer is dependent or independent (Fig. 1).

Fig. 1 does not show the mutual impact of one controlled diagnostic parameter on the other one, it is shown whether the impact of these parameters on the coefficient of total residual resource of the power transformer (PT) is dependent or independent.

In Fig.1, over the diagnostic parameter, the percentage amount of revealed faulty transformers by the given parameter is shown, that is given in percent of the total amount of faulty transformers, and $k_{\text {res }}$ - residual resource coefficient of the transformer (RRCT).

The blocks with parameters, whose deviations from the norm substantiate the necessity of removing the transformers out of service, are shown sequentially. In parallel, blocks with parameters are also depicted. A large change in these parameters proves the necessity of removing a power transformer (PT) out of service. PT is repaired in case of deviation from the norms of these parameters. This is due to the requirements for the reliability of the transformers. In each of the given blocks, parallel can be allocated but they are not shown to simplify the calculation (for instance, currents of electric motors of oil pumps and fans).

In order to obtain the generalized parameter of the residual resource of the transformer, it is proposed to pass from the known values of diagnostic parameters to the corresponding values of residual resources coefficients (in relative units) by each diagnostic parameter. This will allow you to take into account the values of all diagnostic parameters and the impact of each of them.
These coefficients are defined in relative units by (1) and that is why they characterize the total output of the transformers from the moment of their technical state control to transition to the boundary state that is residual technical resource (12). The residual resource coefficient $k_{i_{1}}$ by the $i_{1}^{\text {th }}$ diagnostic parameter:

$$
k_{i_{1}}=\left|\frac{x_{i_{1}, \text { lim }}-x_{i_{1}, \mathrm{cur} r}}{x_{i_{1}, \mathrm{lim}}-x_{i_{1}, \text { in }}}\right|,
$$

where $x_{i_{1}, \mathrm{lim}}$ is the admissible limit normative value of the $i_{i}^{1 h}$ diagnostic parameter; $x_{i, \text { cur }}$ is the value of the $i_{1}^{\text {th }}$ diagnostic parameter at the moment of control; $x_{i, i n}$ is the initial value of the $i_{i}^{1 h}$ diagnostic parameter (at the moment of putting into operation of new equipment or after repair), $i_{1}$ is the number of the diagnostic parameter.

We perform the reduction of the circuit by the following expressions. For serial part of the circuit (Fig. 1), the coefficient of total residual resource is found by the expression:

$$
k_{\text {tot.resid.res. }}=\prod_{\tau=1}^{v} k_{\tau}^{p_{\tau}}
$$

where $k_{\tau}$ is the coefficient of residual resource of PT by the $\tau^{\text {th }}$ diagnostic parameter; $\tau$ is the $\tau^{\text {th }}$ diagnostic parameter; $v$ is the amount of blocks in the serial part of the circuit of Fig.1, $p_{\tau}$ - the probability of control parameters deviations from the maximum permissible normalized value of this parameter is found by means of the expression (3):

$$
p_{\tau}=\frac{y_{\tau}}{m_{2}}
$$

where $y_{\tau}$ is the number of controlled parameter deviations from the admissible limiting normalized value of this parameter, which were revealed by means of the $\tau^{\text {th }}$ diagnostic parameter control ( $\tau$ - for the serial part of the circuit) from the total number of the revealed deviations of controlled parameters from the admissible limiting normalized value; $m_{2}$ is the total quantity of the revealed deviations of controlled diagnostic parameter from their admissible limiting normalized values.

For the parallel part of the circuit, the coefficient of total residual resource is found by the expression (4)

$$
k_{p e c \Sigma}=1-\sum_{j=1}^{m 1}\left[\left(1-k_{r e s, j}\right) p_{j}\right]
$$

where $k_{\text {res, } j}$ is the coefficient of residual resource of PT by the $j^{\text {th }}$ diagnostic parameter; $j$ is the number of the $j^{\text {th }}$ diagnostic parameter; $m_{1}$ is the number of blocks (parameters) in the parallel part of the circuit that is reduced.

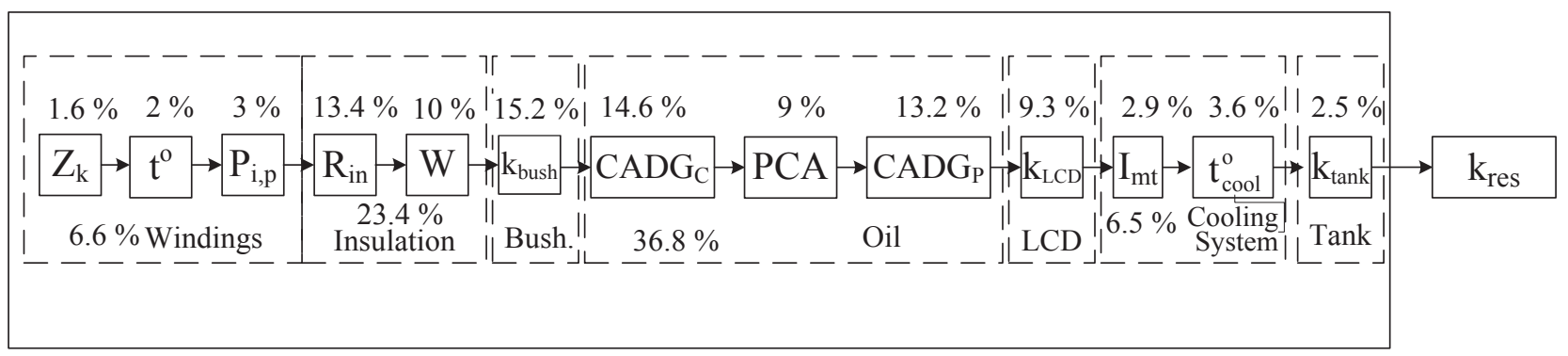

Fig. 1. Structural diagram of the model of total residual resource coefficient of the transformer 
The coefficient of total residual resource of PT is determined by the expression (5):

$$
k_{\text {res. }}=k_{\text {wind. }} \cdot k_{\text {in. }} \cdot k_{\text {bush }} \cdot k_{\text {oil }} \cdot k_{\text {LTC }} \cdot k_{\text {cool }} \cdot k_{\text {tank }} \text {, }
$$

where $k_{\text {wind, }}, k_{\text {in. }}, k_{\text {bush }}, k_{\text {oil }}, k_{\text {LTC }}, k_{\text {cool }}, k_{\text {tank }}$ are known at the moment of calculation values of the coefficient of residual resource of: the windings, insulation, bushings, oil, LTC, cooling system, ank of the transformer, by the elements of the transformer, correspondingly.

\subsection{Neuro-fuzzy model of residual resource coefficient}

For the creation of a mathematical model of the residual resource coefficient of the transformer, the parameters were used, by each of these parameters the conclusion regarding the state of the transformer can be made. But none of these parameters completely characterize the technical state of the transformer, it only shows certain changes of the technical state of the power transformer.

A mathematical model of the residual resource coefficient of the transformer was created by means of MatLab. Using this model, it is possible to edit the already created (5) probabilistic sample of training data. These data help to obtain an analytical dependence of the residual resource coefficient of the transformer on the diagnostic parameters in the form of the polynomial. For seven input parameters of the model that randomly changed from 0 to 1 , the coefficient of total residual resource of the transformer (5) was determined, where input parameters of the model were reduced to relative units of their deviation from the norm.

By means of Anfis Editor using the hybrid training algorithm and applying the Sugeno fuzzy inference algorithm, the neuro-fuzzy model of the residual resource coefficient of the transformer (using subclusterization method) was obtained.

Fig. 2 contains the copy of the screen saver in the Matlab environment where the structure of the obtained neural network is shown.

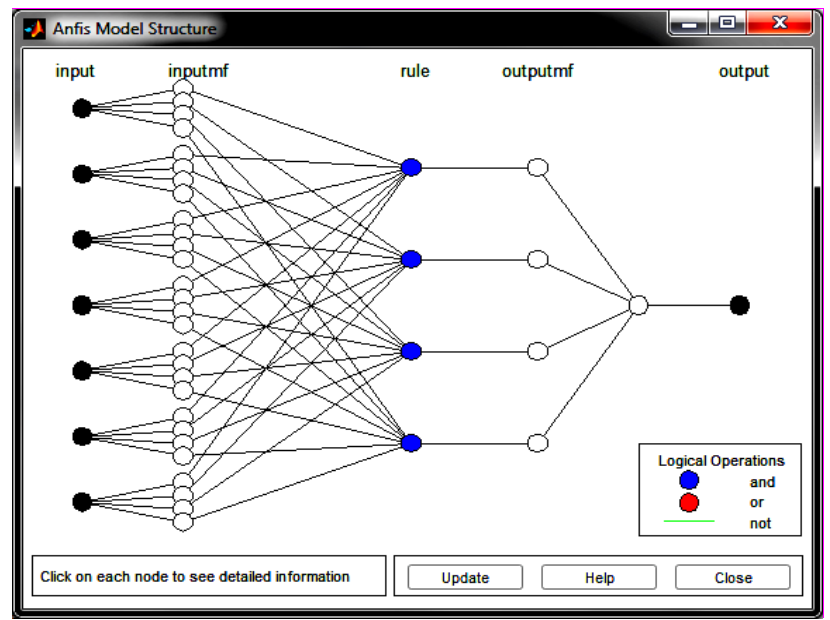

Fig. 2. Structure of the Anfis-network of the transformer

For each input variable of the neuro-model, four linguistic terms with Gaussian membership functions were used:

$$
k_{p e c . i 1}=f\left(x_{i 1} ; \sigma_{i 1} ; c_{i 1}\right)=e^{\frac{-\left(x_{i 1}-c_{i 1}\right)^{2}}{2 \sigma_{i 1}^{2}}},
$$

where $\sigma_{1}$ and $c_{1}$ are numerical parameters; $\sigma_{1}^{2}-$ in the probability theory it is called the variance of distribution (14), and the second parameter $c_{1}$ is the mathematical expectation; $i_{1}$ - is the input parameter of the neural-fuzzy model that corresponds to the diagnostic parameter $\left(i_{1}=1,2,3,4,5,6,7\right), x_{\mathrm{i}}$ is the value of the $\mathrm{i}_{1}$ th input parameter of the model: $\mathrm{x}_{1}-k_{\text {zind. }}$, $\mathrm{x}_{2}-k_{\text {in. }}, \mathrm{x}_{3}-k_{\text {bush }}, \mathrm{x}_{4}-k_{\text {oil }}, \mathrm{x}_{5}-k_{L T C}, \mathrm{x}_{6}-k_{\text {cool }}, \mathrm{x}_{7}-k_{\text {tank } k}$.

These are such terms as: "normal" values of the diagnostic parameter, "minor deviations" of the diagnostic parameter value, "prefault" values of the diagnostic parameter, "emergency" value of the diagnostic parameter.

For determining the value of the total residual coefficient, a fuzzy non-linear autoregressive model of the total residual resource coefficient of the transformer is used. This model establishes fuzzy non-linear transformation between the values of the residual resource coefficients by the diagnostic parameters and the total residual resource coefficient of the transformer (7):

$$
k_{\text {tot.resid.res }}=F\left(k_{\text {weind }}, k_{\text {in. }}, k_{\text {bush }}, k_{\text {oil }}, k_{\text {LTC }}, k_{\text {cool }}, k_{\tan k}\right) \text {, }
$$

where $F$ is fuzzy functional transformation.

For determination of the value of the total residual resource coefficient of the transformer, we use the Takagi-Sugeno logic inference model.

The mathematical model of the total residual resource coefficient is the system of logic equations (8).

$$
\begin{aligned}
& \int I F k_{\text {weind. }} \in \text { "normal" AND } k_{\text {in. }} \in \text { "normal" } \\
& A N D k_{\text {gush }} \in \text { "normal" } \\
& A N D k_{\text {oil }} \in \text { "normal " AND } k_{L T C} \in \text { "normal" } \\
& A N D k_{\text {cool. }} \in \text { "normal" } \\
& A N D k_{\tan k} \in \text { "normal"THEN } \\
& k_{\text {tot.resid.res }}=a_{11} \cdot k_{\text {wind. }}+a_{12} \cdot k_{\text {in. }}+a_{13} \cdot k_{\text {bush. }}+a_{14} \cdot k_{\text {oil }}+ \\
& +a_{15} \cdot k_{\text {LTC }}+a_{16} \cdot k_{\text {cool. }}+a_{17} \cdot k_{\text {tan } k}+c_{1} \\
& \text { IF } k_{\text {zind }} \in \text { "min or deviations } \\
& A N D k_{\text {in }} \in \text { "min or deviation" } \\
& A N D k_{B \theta} \in \text { "min or deviation" } \\
& A N D k_{\text {oil }} \in \text { "min or deviation" } \\
& A N D k_{L T C} \in \text { "min or deviation" } \\
& A N D k_{\text {cool }} \in \text { "min or deviation" } \\
& A N D k_{\tan k} \in \text { "min or deviation"THEN } \\
& k_{\text {tot.resid.res }}=a_{21} \cdot k_{\text {wind. }}+a_{22} \cdot k_{\text {in. }}+a_{23} \cdot k_{\text {bush. }}+ \\
& +a_{24} \cdot k_{\text {oil }}+a_{25} \cdot k_{\text {LTC }}+a_{26} \cdot k_{\text {cool. }}+a_{27} \cdot k_{\text {tank }}+c_{2} \\
& I F k_{\text {wind }} \in \text { " prefault "AND } k_{\text {in }} \in \text { " prefault" } \\
& A N D k_{\theta B} \in \text { " prefault" } A N D k_{\text {oil }} \in \text { " prefault" } \\
& A N D k_{L T C} \in \text { " prefault" } A N D k_{\text {cool. }} \in \text { " prefault" } \\
& A N D k_{\tan k} \in \text { " prefault"THEN } \\
& k_{\text {tot.resid.res }}=a_{31} \cdot k_{\text {wind. }}+a_{32} \cdot k_{\text {in. }}+a_{33} \cdot k_{\text {bush. }}+a_{34} \cdot k_{\text {oil }}+ \\
& +a_{35} \cdot k_{\text {LTC }}+a_{36} \cdot k_{\text {cool. }}+a_{37} \cdot k_{\tan k}+c_{3} \\
& \text { IF } k_{\text {wind }} \in \text { "emergency " AND } k_{\text {in }} \in \text { "emergency" } \\
& A N D k_{\theta B} \in \text { "emergency" } A N D k_{\text {oil }} \in \text { "emergency" } \\
& A N D k_{L T C} \in \text { "emergency" } A N D k_{\text {cool. }} \in \text { "emergency" } \\
& A N D k_{\text {tan } k} \in \text { "emergency" THEN } \\
& k_{\text {tot.resid.res }}=a_{41} \cdot k_{\text {wind. }}+a_{42} \cdot k_{\text {in. }}+a_{43} \cdot k_{\text {bush. }}+a_{44} \cdot k_{\text {oil }}+ \\
& +a_{45} \cdot k_{L T C}+a_{46} \cdot k_{\text {cool. }}+a_{47} \cdot k_{\tan k}+c_{4}
\end{aligned}
$$


The output of the model total $k_{\text {tot.resid.res. }}$ is found as a weighted sum of conclusions (8) of the rule base written in the form of the system of logic equations:

$$
k_{\text {tot.resid.res. }}=\sum_{j 2=1}^{m 3} w_{j 2}\left(\begin{array}{l}
a_{j 21} \cdot k_{\text {wind }}+a_{j 22} \cdot k_{i n}+ \\
+a_{j 23} \cdot k_{\text {bush. }}+a_{j 24} \cdot k_{\text {oil. }}+ \\
+a_{j 25} \cdot k_{L T C}+a_{j 26} \cdot k_{\text {cool. }}+ \\
+a_{j 27} \cdot k_{\tan k}+c_{j 2}
\end{array}\right)
$$

where $0 \leq w_{j 2} \leq 1$ is the degree of execution (weight) of the $j_{2}$-th rule that is determined by the correspondence of real changes of diagnostic parameters of the transformer.

ANFIS is the simplest network of direct propagation that contains adaptive nodes. Using the training rules, the parameters of these nodes are arranged so as to minimize the error between the real output of the model $k_{\text {tot.resid.mod. }}$ and the real total residual resource coefficient $k_{\text {tot.resid.res }}$ of the transformer

$$
\delta=\sqrt{\frac{1}{N_{1}} \sum_{k_{3}=0}^{N_{1}-1}\left(k_{\text {tot.resid.res. } \bmod k 3}-k_{\text {tot.resid.res. } k 3}\right)^{2}} \rightarrow \min ,
$$

where $N$ is the number of rows in the training sample; $k_{3}$ is the number of the row in the training sample, starting from the row with the sequence number " 0 ".

Taking into account the iterative computation experiments carried out, the vector of membership functions parameters is determined in Table 2.

Table 2

\begin{tabular}{|c|c|c|c|c|c|}
\hline \multirow{2}{*}{ Parameters } & \multirow{2}{*}{$\begin{array}{l}\text { Input parameters of } \\
\text { the model }\end{array}$} & \multirow{2}{*}{ Name of the term } & \multirow{2}{*}{ Number of the rule } & \multicolumn{2}{|c|}{ Parameters of membership functions } \\
\hline & & & & $\sigma$ & $\mathrm{C}$ \\
\hline \multirow{4}{*}{ Winding state } & \multirow{4}{*}{$K_{\text {wind. }}$} & Normal & 1 & 0.3825 & 0.7944 \\
\hline & & Minor deviation & 2 & 0.479 & 0.5197 \\
\hline & & Prefault & 3 & 0.4903 & 0.5668 \\
\hline & & Emergency & 4 & 0.4 & 0.1697 \\
\hline \multirow{4}{*}{ Insulation state } & \multirow{4}{*}{$k_{\text {in }}$} & Normal & 1 & 0.3653 & 0.8698 \\
\hline & & Minor deviation & 2 & 0.4642 & 0.6104 \\
\hline & & Prefault & 3 & 0.5102 & 0.5267 \\
\hline & & Emergency & 4 & 0.3949 & 0.1742 \\
\hline \multirow{4}{*}{ State of BB } & \multirow{4}{*}{$k_{\text {bush }}$} & Normal & 1 & 0.3202 & 0.9221 \\
\hline & & Minor deviation & 2 & 0.3419 & 0.7649 \\
\hline & & Prefault & 3 & 0.4914 & 0.5376 \\
\hline & & Emergency & 4 & 0.4032 & 0.1925 \\
\hline \multirow{4}{*}{ State of oil } & \multirow{4}{*}{$K_{o i l}$} & Normal & 1 & 0.4369 & 0.9273 \\
\hline & & Minor deviation & 2 & 0.3404 & 0.9674 \\
\hline & & Prefault & 3 & 0.412 & 0.599 \\
\hline & & Emergency & 4 & 0.4031 & 0.2057 \\
\hline \multirow{4}{*}{ State LTC } & \multirow{4}{*}{$K_{L T C}$} & Normal & 1 & 0.3984 & 0.973 \\
\hline & & Minor deviation & 2 & 0.3316 & 0.963 \\
\hline & & Prefault & 3 & 0.4468 & 0.5881 \\
\hline & & Emergency & 4 & 0.4428 & 0.2349 \\
\hline \multirow{4}{*}{$\begin{array}{l}\text { State of cooling } \\
\text { system }\end{array}$} & \multirow{4}{*}{$k_{\text {cool. }}$} & Normal & 1 & 0.3439 & 1.153 \\
\hline & & Minor deviation & 2 & 0.3507 & 0.9706 \\
\hline & & Prefault & 3 & 0.437 & 0.597 \\
\hline & & Emergency & 4 & 0.4263 & 0.2397 \\
\hline \multirow{4}{*}{ State of tank } & \multirow{4}{*}{$K_{\text {tank }}$} & Normal & 1 & 0.3454 & 0.9506 \\
\hline & & Minor deviation & 2 & 0.3801 & 1.017 \\
\hline & & Prefault & 3 & 0.4582 & 0.6273 \\
\hline & & Emergency & 2 & 0.5451 & 0.564 \\
\hline
\end{tabular}

Parameters of membership functions 
Taking into account the data of Table 1, 2 and (9), we obtain the mathematical model of the coefficient of total residual resource in the form:

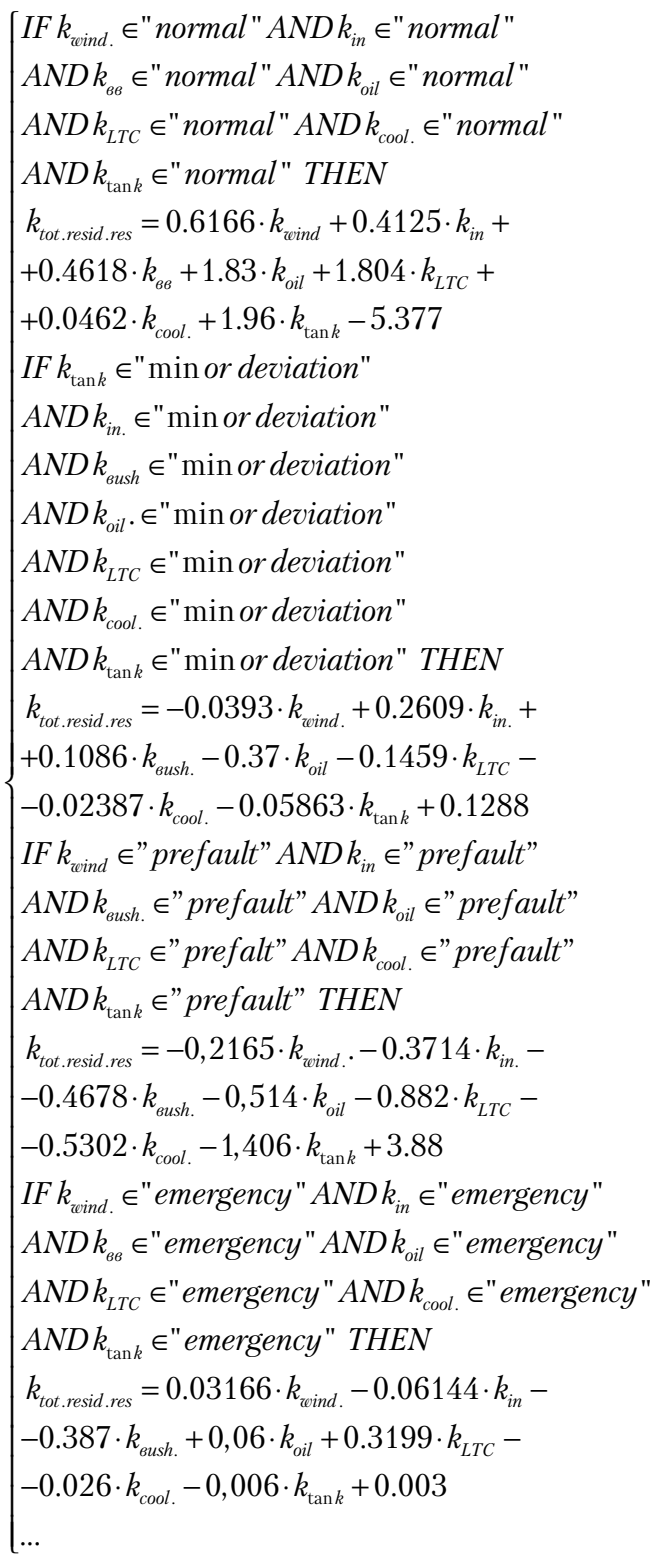

It is seen from Fig. 2 that in the process of formation of the structure of neuro- fuzzy model of the transformer, seven inputs and one output of this model were set. Each of seven inputs has four terms. That is, each set of possible values of input parameters of the model is conventionally divided into four subsets: "normal" values of the input parameter, "minor deviations" of the values of the input parameter, and "prefault" values of the input parameter, "emergency" values of the input parameter. The degree of membership of each value of the input parameter in the corresponding set of values is determined by a Gaussian membership function. The model is intended for determining the numerical value of the total residual resource coefficient of the transformer, that is why it has one output. This numerical value is found by means of solving the linear equation that describes the dependence of the coefficient of total residual resource of the transformer on the input parameters.

The obtained neuro-fuzzy model allows determining the value of the total residual resource coefficient of the transformer depending on the values of input parameters residual resources coefficients by each of the controlled diagnostic parameters. The error of the PPCT mathematical model changes from +0.004 relative units, if PPCT equals 0 , to -0.032 , when PPCT equals 1.

Despite the complexity of dependences, the mathematical model of the residual resource coefficient of the transformer (11) may be used for programming the fuzzy controller in order to create the device for on-line determination of the transformer state by means of analysis of the residual resource coefficient value of the transformer.

\section{Account of the projected current value of the residual resource of the transformers in the process of optimal control of EES modes}

It is known that in the process of operation, an energy enterprise plans to remove out of service the equipment in the overhaul, the cost of is projected. Removal of the transformer into overhaul in a planned number of years $\left(\mathrm{T}_{\mathrm{WF}}\right)$ of trouble-free operation (12 years) provides for a certain list of works and their expected cost $B_{\text {ohpl. }}$ For instance, for $330 / 110 \mathrm{kV}$ transformers of 125-250 MVA power, the cost (B) of such repair is 770-11550 \$. We propose to assume that removal of transformers out of service into current repair requires unscheduled expenses.

The cost of repair may increase by the value $\Delta B_{1}$, the cost of replacement of damaged blocks of the transformer and additional work, connected with the replacement. These costs are not provided in case of "typical" planned overhaul

$$
\Delta B_{1}=\sum_{i=1}^{n}\left(B_{i} \cdot e^{\gamma_{i} \cdot k_{r s s i}^{\beta_{i}}}\right)
$$

where $B_{i}$ is the cost of replacement of the $i^{\text {th }}$ damaged block of the transformer and additional work, connected with this replacement, $\mathrm{n}$ is the number of damaged blocks that require unscheduled replacement; $k_{r e s,}^{\beta_{i}}$ is the residual resource coefficient of the $i^{\text {th }}$ block that requires unscheduled replacement; $\gamma$ and $\beta$ are the coefficients that characterize the impact of the residual resource coefficient on the expected cost of unscheduled repair or replacement of the $i^{\text {th }}$ block of the transformer (is determined by means of processing of statistical data).

Repair cost may increase by the cost of $\Delta B_{2}$ (as compared with expected) in case of enlarged current (instead of planned overhaul) repair of the transformer; that has not operated for the planned number of years:

$$
\Delta B_{2_{j}}=\left(1-\mathrm{e}^{\alpha_{j}\left(\mathrm{~T}_{\mathrm{j}}-1\right)}\right) \cdot B_{O H},
$$

where $j$ is the number of the transformer, $T_{j}$ is the time the $i^{\text {th }}$ transformer functioned after putting into operation or after the last overhaul (enlarged current) repair until the moment of mode control, $\lambda$ is the coefficient that characterizes the intensity of the $\Delta B_{2}$ cost growth that depends on the transformer design, operation conditions and modes (is determined experimentally), $B_{O H}$ is the cost of the transformer overhaul.

It should be noted that removal of the transformer out of service takes place not only as a result of relay protection, emergencies control automation operation but also is made by a person responsible for safe operation by the results of control of diagnostic parameters, the values of which sometimes only approach to limiting values. 
Within the context of creation of modern Smart Grids and to provide safe, reliable, high-quality and economic efficient operation of EES, it is necessary to perform the control over active power overflow by means of the transformer, performing reliable and information actions on the mode. That is why, we propose to take into account the coefficient of regulating transformer limitation:

$$
k_{\text {zind }, j}=\left(1-k_{r e s, j}\right) \cdot B_{c q, j},
$$

where $B_{c q}$ is the coefficient of repair cost value growth of the $j^{\text {th }}$ transformer.

$$
B_{c q, j}=\frac{\Delta B_{1, j}+\Delta B_{2, j}}{\Delta B_{1, j}+B_{p l ., j}} .
$$

As an example, we will consider 23 nodes 230/138 $\mathrm{kV}$ test circuit, (Fig. 3) In branches 11-9, 12-14, 129, 11-4, and 3-7, transformers ATDCTN-63000/230/ 138, ATDCTN-100000/230/138 and ATDCTN-125000/ $230 / 138$ are installed. Initial node loads, complex transformation ratios and corresponding LTC transformers positions (numbers of taps) are given in Tables 3, 4 .

Table 3

\begin{tabular}{|c|c|c|c|c|c|}
\hline \multicolumn{2}{|c|}{ Branches } & \multirow{2}{*}{$R, \mathrm{Ohm}$} & \multirow{2}{*}{$X, \mathrm{Ohm}$} & \multirow{2}{*}{$k_{\text {active }}$} & \multirow{2}{*}{$k_{\text {reactive }}$} \\
\hline No. of beginning & No. of the end & & & & \\
\hline 11 & 10 & 0.6 & 27 & 0.6487 & 0 \\
\hline 12 & 9 & 0.37 & 9.28 & 0.6498 & 0 \\
\hline 11 & 9 & 0.3 & 13 & 0.6479 & 0 \\
\hline 7 & 3 & 0.21 & 11.53 & 0.65 & 0 \\
\hline 1 & 2 & 0.4951 & 2.6471 & 1 & 0 \\
\hline 1 & 3 & 10.398 & 40.221 & 1 & 0 \\
\hline 1 & 5 & 4.1516 & 16.092 & 1 & 0 \\
\hline 2 & 4 & 6.2464 & 24.129 & 1 & 0 \\
\hline 2 & 6 & 9.4649 & 36.565 & 1 & 0 \\
\hline 3 & 9 & 9.882 & 20.962 & 1 & 0 \\
\hline 4 & 9 & 5.1038 & 19.749 & 1 & 0 \\
\hline 5 & 10 & 4.342 & 16.816 & 1 & 0 \\
\hline 8 & 9 & 8.82 & 15.124 & 1 & 0 \\
\hline 8 & 10 & 2.067 & 2.145 & 1 & 0 \\
\hline 11 & 23 & 5.207 & 22.793 & 1 & 0 \\
\hline 11 & 14 & 2.8566 & 22.112 & 1 & 0 \\
\hline 12 & 23 & 5.207 & 25.18 & 1 & 0 \\
\hline 12 & 13 & 6.5596 & 51.101 & 1 & 0 \\
\hline 23 & 13 & 5.8719 & 45.759 & 1 & 0 \\
\hline 14 & 16 & 2.645 & 20.578 & 1 & 0 \\
\hline 15 & 16 & 2.338 & 8.404 & 1 & 0 \\
\hline 16 & 17 & 1.7457 & 13.701 & 1 & 0 \\
\hline 16 & 19 & 3.117 & 11.206 & 1 & 0 \\
\hline 17 & 18 & 0.9522 & 7.6176 & 1 & 0 \\
\hline 17 & 22 & 7.1415 & 55.704 & 1 & 0 \\
\hline 21 & 22 & 4.6023 & 35.866 & 1 & 0 \\
\hline 7 & 15 & 5.68 & 24.865 & 1 & 0 \\
\hline 21 & 18 & 0.873 & 6.851 & 1 & 0 \\
\hline 21 & 15 & 1.666 & 12.96 & 1 & 0 \\
\hline 19 & 20 & 1.349 & 10.474 & 1 & 0 \\
\hline 20 & 13 & 0.741 & 5.713 & \begin{tabular}{|l|}
1 \\
\end{tabular} & 0 \\
\hline 12 & 10 & 0.31 & 14 & 0.6524 & 0 \\
\hline 10 & 6 & 2.6471 & 11.522 & 1 & 0 \\
\hline
\end{tabular}

Information on the circuit branches

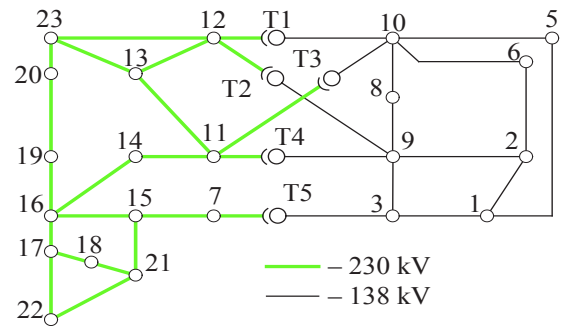

Fig. 3. Scheme of the 23 nodes $230 / 138 \mathrm{kV}$ circuit

Table 4

Information ef on the circuit nodes

\begin{tabular}{|c|c|c|c|c|c|c|}
\hline $\begin{array}{c}\text { No. } \\
\text { of the } \\
\text { node }\end{array}$ & $U, \mathrm{kV}$ & Phase & $\begin{array}{c}P_{\text {load }}, \\
\mathrm{MW}\end{array}$ & $\begin{array}{c}Q_{\text {load, }}, \\
\mathrm{MVAr}\end{array}$ & $\begin{array}{c}P_{\text {gen }}, \\
\mathrm{MW}\end{array}$ & $\begin{array}{c}Q_{\text {gen }}, \\
\mathrm{MW}\end{array}$ \\
\hline 1 & 136.34 & -5.73 & 108 & 22 & 182 & 30 \\
\hline 2 & 135.54 & -6.27 & 187.15 & 76 & 172.9 & 30 \\
\hline 3 & 141.22 & -0.94 & 176.4 & 36.26 & 0 & 0 \\
\hline 4 & 136 & -8.2 & 74 & 15 & 0 & 0 \\
\hline 5 & 137 & -8.11 & 68.16 & 13.44 & 0 & 0 \\
\hline 6 & 136.36 & -10.3 & 129.2 & 25.27 & 0 & 0 \\
\hline 7 & 218.84 & 2.99 & 19.4 & 1.94 & 0 & 0 \\
\hline 8 & 142.57 & -7.72 & 169.29 & 34.65 & 131.55 & 131.75 \\
\hline 9 & 141.55 & -5.6 & 275 & 66 & 0 & 0 \\
\hline 10 & 141.64 & -7.29 & 191.1 & 49 & 0 & 0 \\
\hline 11 & 222.36 & -3.12 & 40 & 10 & 0 & 0 \\
\hline 12 & 219.92 & -4.12 & 54.88 & 17.64 & 0 & 0 \\
\hline 13 & 236.15 & 7.89 & 0 & 0 & 495 & 150 \\
\hline 14 & 228.34 & 1.56 & 184.3 & 37.05 & 0 & 101.39 \\
\hline 15 & 233.22 & 11.21 & 304.32 & 61.44 & 235.2 & 51.32 \\
\hline 16 & 233.45 & 10 & 100 & 20 & 185 & 80 \\
\hline 17 & 237.79 & 15.28 & 35.64 & 13.86 & 0 & 0 \\
\hline 18 & 241.5 & 16.92 & 323.01 & 65.96 & 417.1 & 176.19 \\
\hline 19 & 231.47 & 7.6 & 177.38 & 36.26 & 0 & 0 \\
\hline 20 & 233.81 & 7.31 & 128 & 26 & 0 & 0 \\
\hline 21 & 241.5 & 17.83 & 0 & 0 & 425.7 & 146 \\
\hline 22 & 241.5 & 25.5 & 0 & 0 & 420 & -3.69 \\
\hline 23 & 234.6 & 0 & 265 & 54 & 417.85 & 281.37 \\
\hline
\end{tabular}

Knowing the circuit and normal node parameters, we define optimal transformation ratios

$$
\begin{aligned}
& k_{a . o p t}=1-\operatorname{diag}\left(\operatorname{Re}\left(-N_{k . b a l_{\cdot}} \cdot Z \cdot C_{e} \cdot J\right)\right) \cdot U_{b}^{-1} \cdot E_{b a l_{a}}^{*}, \\
& k_{r . o p t}=-\operatorname{diag}\left(\operatorname{Im}\left(-N_{k z_{b}} \cdot Z \cdot C_{e} \cdot J\right)\right) \cdot U_{b}^{-1} \cdot E_{z r_{p}}^{*},
\end{aligned}
$$

where $N_{k . b a l . b}$ is the second matrix of branches connection in contour for balanced transformation ratios; $Z$ is the diagonal matrix of complex branches resistances; $C_{e}$ is the matrix of the currents distribution coefficients for saving mode of electric network (corresponds to minimal losses of electric energy); $J$ is the vector-column of currents in nodes; $U_{b}$ is the voltage of the basic node; $E_{b a l_{a}}^{*}, E_{z r_{p}}^{*}$ are optimal balancing electromotive forces (EMF) in relative units (active and reactive components).

Taking into consideration the discrete character of LTC switching, errors of measurement transformers, errors of data transmission channels and recommendations [2], we assume that the non-sensitivity zone of active power losses 
may be considered as regulating actions on LTC of the transformer $-3 \%[5]$.

As initial conditions, we assume that in accordance with the load graph of LTC transformers 9-11, 9-12, 11-10, 12-10 have transformation ratios 0.6413 (14 tap), 0.6347 (14 tap), 0.6397 (14 tap), 06446 (14 tap). It should be noted that further changes of the operation mode were realized at admissible voltage deviations $\pm 5 \%$ of the nominal voltage $U_{\text {nom }}$. Regulation of the transformer $7-3$ is inexpedient on conditions of the usage of the given technique of determination of optimal transformation ratios.

We define the losses of active and reactive power in the branches of the circuit at current transformation ratios (Table 5)

$$
\Delta \mathbf{S}_{\Sigma b r}=\Delta \mathbf{P}_{\Sigma b r}+j \Delta \mathbf{Q}_{\Sigma b r}=3 \cdot \sum_{j=1}^{m} \Delta \mathbf{S}_{b r, j},
$$

where $\Delta \mathbf{S}_{b r}=\operatorname{diag}\left(\Delta \mathbf{U}_{b r}\right) \cdot \hat{\mathbf{I}}_{b r}$ is the vector-column of complete power losses in the branches of the circuit. $\hat{\mathbf{I}}_{b r}$ is the vector-column of the current in branches, $m$ is the number of the branch in the circuit, $\Delta \mathbf{U}_{\mathrm{br}}=\mathbf{M}_{\Sigma} \cdot \mathbf{U}_{\text {node }}$ is the vector-column of phase voltages in the nodes, $\Delta \mathbf{P}_{b r}, \Delta \mathbf{Q}_{b r}$ is the vector-column of active and reactive power losses in the branches of the circuit (correspondingly).

We define optimal transformation ratios (16), (17) and position of LTC on condition of the minimal number of switchings (in order to maintain switching resources of LTC) to provide minimal losses of active power in branches of the circuit of Table 6 .

Table 5

Parameters of the current mode

\begin{tabular}{|c|c|c|c|c|c|c|c|c|c|c|c|c|c|c|c|c|c|c|c|c|c|c|c|}
\hline \multirow{2}{*}{$P$-ters* } & \multicolumn{23}{|c|}{ No. of nodes } \\
\hline & 1 & 2 & 3 & 4 & 5 & 6 & 7 & 8 & 9 & 10 & 11 & 12 & 13 & 14 & 15 & 16 & 17 & 18 & 19 & 20 & 21 & 22 & 23 \\
\hline $\begin{array}{l}P_{\text {load, }} \\
\text { MW }\end{array}$ & 19.44 & 37.43 & 38.8 & 17.02 & 13.63 & 24.55 & 3.49 & 27.08 & 60.5 & 38.22 & 8.4 & 10.43 & 0 & 29.49 & 39.6 & 20 & 8.55 & 80.75 & 35.47 & 26.88 & 0 & 0 & 53 \\
\hline $\begin{array}{l}Q_{\text {load }} \\
\text { MVAr }\end{array}$ & 3.96 & $\mid 15.2$ & 7.97 & 3.45 & 2.69 & 4.8 & 0.35 & 5.54 & 14.52 & 9.8 & 2.1 & 3.35 & 0 & 5.93 & 8 & 4 & 3.33 & 16.49 & 7.25 & 5.46 & 0 & 0 & 10.8 \\
\hline $\begin{array}{l}\Delta P_{\Sigma} \\
M W\end{array}$ & \multicolumn{23}{|c|}{4.49} \\
\hline $\begin{array}{l}\Delta Q_{\Sigma}, \\
\text { MVar }\end{array}$ & \multicolumn{23}{|c|}{29.05} \\
\hline $11-10$ & - & - & - & - & - & - & - & - & - & 0.64 & & - & - & - & - & - & - & - & - & - & - & - & - \\
\hline No. tap & - & - & - & - & - & - & - & - & - & 14 & & - & - & - & - & - & - & - & - & - & - & - & - \\
\hline $12-10$ & - & - & - & - & - & - & - & - & - & \multicolumn{3}{|c|}{0.6446} & - & - & - & - & - & - & - & - & - & - & - \\
\hline No. tap & - & - & - & - & - & - & - & - & - & \multicolumn{3}{|c|}{14} & - & - & - & - & - & - & - & - & - & - & - \\
\hline $9-11$ & - & - & - & - & - & - & - & - & \multicolumn{3}{|c|}{0.6413} & - & - & - & - & - & - & - & - & - & - & - & - \\
\hline No. tap & - & - & - & - & - & - & - & - & \multirow{2}{*}{\multicolumn{4}{|c|}{$\begin{array}{c}\mathbf{1 4} \\
0.6397 \\
\end{array}$}} & - & - & - & - & - & - & - & - & - & - & - \\
\hline 9-12 & - & - & - & - & - & - & - & - & & & & & - & - & - & - & - & - & - & - & - & - & - \\
\hline \begin{tabular}{|l|} 
No. tap \\
\end{tabular} & - & - & - & - & - & - & - & - & \multicolumn{4}{|c|}{13} & - & - & - & - & - & - & - & - & - & - & - \\
\hline \begin{tabular}{|c|}
$9-12$ \\
\end{tabular} & - & - & \multicolumn{5}{|c|}{0.65} & - & - & - & - & - & - & - & - & - & - & - & - & - & - & - & - \\
\hline No. tap & - & - & \multicolumn{5}{|c|}{14} & - & - & - & - & - & - & - & - & - & - & - & - & - & - & - & - \\
\hline
\end{tabular}

Table 6

Optimal transformation ratios for the current mode

\begin{tabular}{|c|c|c|c|c|c|c|c|c|c|c|c|c|c|c|c|c|c|c|c|c|c|c|c|}
\hline \multirow{2}{*}{ P-ters } & \multicolumn{23}{|c|}{ No. of nodes } \\
\hline & 1 & 2 & 3 & 4 & 5 & 6 & 7 & 8 & 9 & 10 & 11 & 12 & 13 & 14 & 15 & 16 & 17 & 18 & 19 & 20 & 21 & 22 & 23 \\
\hline $\begin{array}{l}P_{\text {load }} \\
\text { MW }\end{array}$ & 19.44 & 37.43 & 38.8 & 17.02 & 13.63 & 24.55 & 3.49 & 27.08 & 60.5 & 38.22 & 8.4 & 10.43 & 0 & 29.49 & 39.6 & 20 & 8.55 & 80.75 & 35.47 & 26,88 & 0 & 0 & 53 \\
\hline $\begin{array}{l}Q_{\text {load }}, \\
\text { MVAr }\end{array}$ & 3.96 & 15.2 & 7.97 & 3.45 & 2.69 & 4.8 & 0.35 & 5.54 & 14.52 & 9.8 & 2.1 & 3.35 & 0 & 5.93 & 8 & 4 & 3.33 & 16.49 & 7.25 & 5.46 & 0 & 0 & 10.8 \\
\hline $\begin{array}{l}\Delta P_{\Sigma} \\
\mathrm{MW}\end{array}$ & \multicolumn{23}{|c|}{4.42} \\
\hline $\begin{array}{l}\Delta Q_{\Sigma} \\
\text { MVar }\end{array}$ & \multicolumn{23}{|c|}{28.69} \\
\hline $11-10$ & - & - & - & - & - & - & - & - & - & 0.65 & 513 & - & - & - & - & - & - & - & - & - & - & - & - \\
\hline No. tap & - & - & - & - & - & - & - & - & - & 14 & 4 & - & - & - & - & - & - & - & - & - & - & - & - \\
\hline $12-10$ & - & - & - & - & - & - & - & - & - & \multicolumn{3}{|c|}{0.6542} & - & - & - & - & - & - & - & - & - & - & - \\
\hline No. tap & - & - & - & - & - & - & - & - & - & \multicolumn{3}{|c|}{15} & - & - & - & - & - & - & - & - & - & - & - \\
\hline $9-11$ & - & - & - & - & - & - & - & - & \multicolumn{3}{|c|}{0.6507} & - & - & - & - & - & - & - & - & - & - & - & - \\
\hline № tap & - & - & - & - & - & - & - & - & \multirow{2}{*}{\multicolumn{4}{|c|}{$\begin{array}{c}14 \\
0.6521 \\
\end{array}$}} & - & - & - & - & - & - & - & - & - & - & - \\
\hline $9-12$ & - & - & - & - & - & - & - & - & & & & & - & - & - & - & - & - & - & - & - & - & - \\
\hline No. tap & - & - & - & - & - & - & - & - & \multicolumn{4}{|c|}{14} & - & - & - & - & - & - & - & - & - & - & - \\
\hline $9-12$ & - & - & \multicolumn{5}{|c|}{0.65} & - & - & - & - & - & - & - & - & - & - & - & - & - & - & - & - \\
\hline No. tap & - & - & \multicolumn{5}{|c|}{14} & - & - & - & - & - & - & - & - & - & - & - & - & - & - & - & - \\
\hline
\end{tabular}


As a result of realization of control actions, mode optimization, power losses were reduced from $\Delta S_{1}=4.49+j 29.05$ (MVA) for the mode (Table 5) to $\Delta S_{2}=4.42+j 28.69$ (MVA). Thus, the effect of realization of LTC transformer switchings is $\Delta S_{1}-\Delta S_{2}=0.07+j 0.36$ (MVA). It is possible to perform the transition from the current to optimal mode by switching the LTC transformer, installed in the branch 9-12 from 13 tap to 14 and the transformer regulation by changing the position of LTC from 14 tap to 15 . We will consider the transition to another stage of the daily load graph (load increase), its parameters are given in Table 7 , and optimized transformation ratios and corresponding mode parameters - in Table 8.

As a result of performing control actions, mode optimization, we succeeded in decreasing power losses from $\Delta S_{1}=61.85+j 412.73$ (MVA) for the mode (Table 7) to $\Delta S_{2}=61.80+j 412.68$ (MVA). Thus, the effect of LTC transformer switchings is $\Delta S_{1}-\Delta S_{2}=0.05+j 0.5$ (MVA).
If as a result of determining the coefficient of regulating effect limitation for circuit transformers (Fig. 3), the following values are obtained: $k_{\text {wind }, 9-11}=0.85, k_{\text {wind }, 12-9}=0.4$, $k_{\text {wind }, 11-10}=0.3$ and $k_{\text {wind,12-10 }}=0.2$, then the expected quasi-decrease of losses, taking into account these coefficients will be defined.

Control actions are performed by the transformer, installed in the branch 9-11, namely, we change the position of LTC from 14 tap on 15, in this case, the expected losses of active power are $\Delta P_{9-11}=61.82(\mathrm{MW})$. We find the decrease of active power losses $\Delta P_{\mathrm{S}}-\Delta P_{9-11}=61.85-$ $-61.82=0.03(\mathrm{MW})$, however, having taken into account the coefficient of regulating effect limitation, losses decrease will change and become $\delta P_{\text {quasi.9-11 }}=\left(\Delta P_{\mathrm{S}}-\Delta P_{9-11}\right) \times k_{\text {wind,9-11 }}=$ $=0.0255(\mathrm{MW})$. New quasi-losses $\Delta P_{\text {quasi } .9-11}=\Delta P_{9-11}+$ $+\delta P_{\text {quasi } 9-11}=61.82+0.0255=61.8455(\mathrm{MW})$. The results of the calculation of other transformers are given in Table 9.

Table 7

\section{Parameters of the mode after load change}

\begin{tabular}{|c|c|c|c|c|c|c|c|c|c|c|c|c|c|c|c|c|c|c|c|c|c|c|c|}
\hline \multirow{2}{*}{ P-ters } & \multicolumn{23}{|c|}{ No. of nodes } \\
\hline & 1 & 2 & 3 & 4 & 5 & 6 & 7 & 8 & 9 & 10 & 11 & 12 & 13 & 14 & 15 & 16 & 17 & 18 & 19 & 20 & 21 & 22 & 23 \\
\hline $\begin{array}{l}P_{\text {load }} \\
\text { MW }\end{array}$ & 108 & 187.1 & 176.4 & 74 & 68.16 & 129.2 & 19.4 & 169.2 & 275 & 39.1 & 40 & 54.88 & 0 & 184.3 & 304.3 & 100 & 35.64 & 323.0 & 177.3 & 128 & 0 & 0 & 265 \\
\hline $\begin{array}{l}Q_{\text {load }} \\
\text { MVAr }\end{array}$ & 22 & 76 & 36.26 & 15 & 13.44 & 25.27 & 1.94 & 34.65 & 66 & 10 & 10 & 17.64 & 0 & 37.05 & 61.44 & 20 & 13.86 & 65.96 & 36.26 & 26 & 0 & 0 & 54 \\
\hline $\begin{array}{l}\Delta P_{\Sigma} \\
\mathrm{MW}\end{array}$ & \multicolumn{23}{|c|}{61.85} \\
\hline $\begin{array}{l}\Delta Q_{\Sigma} \\
\text { MVar }\end{array}$ & \multicolumn{23}{|c|}{412.73} \\
\hline $11-10$ & - & - & - & - & - & - & - & - & - & 0.65 & & - & - & - & - & - & - & - & - & - & - & - & - \\
\hline No. tap & - & - & - & - & - & - & - & - & - & 14 & & - & - & - & - & - & - & - & - & - & - & - & - \\
\hline $12-10$ & - & - & - & - & - & - & - & - & - & \multicolumn{3}{|c|}{0.6542} & - & - & - & - & - & - & - & - & - & - & - \\
\hline No. tap & - & - & - & - & - & - & - & - & - & \multicolumn{3}{|c|}{15} & - & - & - & - & - & - & - & - & - & - & - \\
\hline $9-11$ & - & - & - & - & - & - & - & - & \multicolumn{3}{|c|}{\begin{tabular}{l|l}
0.6507 \\
\end{tabular}} & - & - & - & - & - & - & - & - & - & - & - & - \\
\hline No. tap & - & - & - & - & - & - & - & - & & 14 & & - & - & - & - & - & - & - & - & - & - & - & - \\
\hline $9-12$ & - & - & - & - & - & - & - & - & \multicolumn{4}{|c|}{0.6521} & - & - & - & - & - & - & - & - & - & - & - \\
\hline No. tap & - & - & - & - & - & - & - & - & \multicolumn{4}{|c|}{14} & - & - & - & - & - & - & - & - & - & - & - \\
\hline $9-12$ & - & - & \multicolumn{5}{|c|}{0.65} & - & - & - & - & - & - & - & - & - & - & - & - & - & - & - & - \\
\hline No. tap & - & - & \multicolumn{5}{|c|}{14} & - & - & - & - & - & - & - & - & - & - & - & - & - & - & - & - \\
\hline
\end{tabular}

Table 8

Parameters of the optimal mode without taking into account the technical state of the transformers

\begin{tabular}{|c|c|c|c|c|c|c|c|c|c|c|c|c|c|c|c|c|c|c|c|c|c|c|c|}
\hline \multirow{2}{*}{$P$-ters } & \multicolumn{23}{|c|}{ No. of nodes } \\
\hline & 1 & 2 & 3 & 4 & 5 & 6 & 7 & 8 & 9 & 10 & 11 & 12 & 13 & 14 & 15 & 16 & 17 & 18 & 19 & 20 & 21 & 22 & 23 \\
\hline $\begin{array}{l}P_{\text {load }} \\
\text { MW }\end{array}$ & 108 & 187.1 & 176.4 & 74 & 6816 & 129.2 & 19.4 & 169.2 & 275 & 39.1 & 40 & 54.88 & 0 & 184.3 & 304.3 & 100 & 35.64 & 323.0 & 177.3 & 128 & 0 & 0 & 265 \\
\hline $\begin{array}{l}Q_{\text {load }} \\
\text { MVAr }\end{array}$ & 22 & 76 & 36.26 & 15 & 13.44 & 25.27 & 1.94 & 34.65 & 66 & 10 & 10 & 17.64 & 0 & 37.05 & 61.44 & 20 & 13.86 & 65.96 & 36.26 & 26 & 0 & 0 & 54 \\
\hline $\begin{array}{l}\Delta P_{\Sigma} \\
M W\end{array}$ & \multicolumn{23}{|c|}{61.80} \\
\hline $\begin{array}{l}\Delta Q_{\Sigma} \\
\text { MVar }\end{array}$ & \multicolumn{23}{|c|}{412.68} \\
\hline $11-10$ & - & - & - & - & - & - & - & - & - & 0.6 & 65 & - & - & - & - & - & - & - & - & - & - & - & - \\
\hline No. tap & - & - & - & - & - & - & - & - & - & 1 & 6 & - & - & - & - & - & - & - & - & - & - & - & - \\
\hline $12-10$ & - & - & - & - & - & - & - & - & - & \multicolumn{3}{|c|}{0.651} & - & - & - & - & - & - & - & - & - & - & - \\
\hline No. tap & - & - & - & - & - & - & - & - & - & \multicolumn{3}{|c|}{14} & - & - & - & - & - & - & - & - & - & - & - \\
\hline $9-11$ & - & - & - & - & - & - & - & - & \multicolumn{3}{|c|}{\begin{tabular}{l|l} 
\\
\end{tabular}} & - & - & - & - & - & - & - & - & - & - & - & - \\
\hline No. tap & - & - & - & - & - & - & - & - & & 17 & & - & - & - & - & - & - & - & - & - & - & - & - \\
\hline $9-12$ & - & - & - & - & - & - & - & - & \multicolumn{4}{|c|}{0.659} & - & - & - & - & - & - & - & - & - & - & - \\
\hline No. tap & - & - & - & - & - & - & - & - & \multicolumn{4}{|c|}{15} & - & - & - & - & - & - & - & - & - & - & - \\
\hline $7-3$ & - & - & \multicolumn{5}{|c|}{0.65} & - & - & - & - & - & - & - & - & - & - & - & - & - & - & - & - \\
\hline No. tap & - & - & \multicolumn{5}{|c|}{14} & - & - & - & - & - & - & - & - & - & - & - & - & - & - & - & - \\
\hline
\end{tabular}


Table 9 corresponds to the branch with transformer couplings in the

Results of limiting effect coefficients calculation for circuit transformers

\begin{tabular}{|c|c|c|c|c|c|c|c|}
\hline \multirow{2}{*}{$\begin{array}{l}\text { Trans- } \\
\text { former }\end{array}$} & $K_{\text {tr.cur. }}$ & $K_{\text {tr.opt. }}$ & \multirow{2}{*}{$K_{\text {weind.j }}$} & \multirow{2}{*}{$\begin{array}{l}\Delta P_{t r . j} \\
\mathrm{MW}\end{array}$} & \multirow{2}{*}{$\begin{array}{c}\Delta P_{\Sigma}-\Delta P_{t r ; j} \\
\quad \mathrm{MW}\end{array}$} & \multirow{2}{*}{$\begin{array}{c}\delta P_{\text {quasi.j. }} \\
\mathrm{MW}\end{array}$} & \multirow{2}{*}{$\begin{array}{l}\Delta P_{\text {quasi } j} j . \\
\mathrm{MW}\end{array}$} \\
\hline & $N_{\text {cur }}$ & $N_{\text {opt. }}$ & & & & & \\
\hline \multirow{2}{*}{$9-11$} & 0.6507 & 0.659 & \multirow{2}{*}{0.85} & \multirow{2}{*}{61.82} & \multirow{2}{*}{0.03} & \multirow{2}{*}{0.0255} & \multirow{2}{*}{61.8455} \\
\hline & 14 & 15 & & & & & \\
\hline \multirow{2}{*}{$12-9$} & 0.6521 & 0.6419 & \multirow{2}{*}{0.46} & \multirow{2}{*}{61.83} & \multirow{2}{*}{0.02} & \multirow{2}{*}{0.0092} & \multirow{2}{*}{61.8392} \\
\hline & 14 & 13 & & & & & \\
\hline \multirow{2}{*}{$11-10$} & 0.6513 & 0.665 & \multirow{2}{*}{0.34} & \multirow{2}{*}{61.835} & \multirow{2}{*}{0.015} & \multirow{2}{*}{0.0051} & \multirow{2}{*}{61.8401} \\
\hline & 14 & 16 & & & & & \\
\hline \multirow{2}{*}{$12-10$} & 0.6542 & 0.651 & \multirow{2}{*}{0.25} & \multirow{2}{*}{61.84} & \multirow{2}{*}{0.01} & \multirow{2}{*}{0.0025} & \multirow{2}{*}{61.8425} \\
\hline & 15 & 14 & & & & & \\
\hline
\end{tabular}

We find losses of active power in the branch that contains the transformer, as the element of the vector-column of complete power losses in the branches of the circuit by the expression

$$
\Delta P_{\alpha}=\operatorname{Re}\left(\Delta S_{\alpha}\right),
$$

where $\Delta S_{\alpha}=\Delta U_{\alpha} \cdot I_{\alpha}$ is the element of the vector-column of power losses in the branches that contain transformers, $\Delta U_{\alpha}$ is the $k^{\text {th }}$ element of the vector-column of phase voltage drop in the branches, and $I_{\alpha}$ is the current of the branches with transformers couplings, $\alpha$ is the number of the row that vector-column $\Delta S_{b r}$.

The value of quasi-resistance in the $k^{\text {th }}$-branch:

$$
Z_{\alpha}=\frac{\Delta S_{\alpha}}{\hat{\mathrm{I}}_{\alpha}^{2}},
$$

where $\alpha=k+\beta$, where $k$ is the number of the row of the first branch that contains the transformer, $\beta$ is the coefficient of the change of the sequence number of the branch, that contains the transformer, it changes in the range from 0 to $(\psi-1)$, $\psi$ is the number of branches, containing transformers.

Applying this algorithm, according to (20), quasi-resistances of the branches, containing transformers are found. The results of the calculations are given in Table 10.

Table 10

Quasi-resistances of transformers branches of the circuit

\begin{tabular}{|c|c|c|c|c|}
\hline Parameters & $\begin{array}{c}\text { Trans- } \\
\text { former } \\
9-11\end{array}$ & $\begin{array}{c}\text { Trans- } \\
\text { former } \\
12-9\end{array}$ & $\begin{array}{c}\text { Trans- } \\
\text { former } \\
11-10\end{array}$ & $\begin{array}{c}\text { Trans- } \\
\text { former } \\
12-10\end{array}$ \\
\hline $\begin{array}{c}\text { Branch resis- } \\
\text { tance, Ohm }\end{array}$ & $0.3+j 13$ & $0.37+j 9.28$ & $0.3+j 27$ & $0.3+j 14$ \\
\hline $\begin{array}{c}\text { Quasi-resis- } \\
\text { tance of the } \\
\text { branch, Ohm }\end{array}$ & $0.32+j 25.2$ & $0.4+j 13.2$ & $0.36+j 28.4$ & $0.35+j 19.2$ \\
\hline
\end{tabular}

We define mode parameters for the circuit with quasi-resistances from Table 11 and optimal corrected transformation ratios from Table 12.

Table 11

\begin{tabular}{|c|c|c|c|c|c|c|c|c|c|c|c|c|c|c|c|c|c|c|c|c|c|c|c|}
\hline \multirow{2}{*}{ P-ters } & \multicolumn{23}{|c|}{ No. of nodes } \\
\hline & 1 & 2 & 3 & 4 & 5 & 6 & 7 & 8 & 9 & 10 & 11 & 12 & 13 & 14 & 15 & 16 & 17 & 18 & 19 & 20 & 21 & 22 & 23 \\
\hline $\begin{array}{l}P_{\text {load, }} \\
\text { MW }\end{array}$ & 108 & 187.1 & 176.4 & 74 & 68.16 & 129.2 & 19.4 & 169.2 & 275 & 39.1 & 40 & 54.88 & 0 & 18.3 & 304.3 & 100 & 35.64 & 323.0 & 177.3 & 128 & 0 & 0 & 265 \\
\hline $\begin{array}{l}Q_{\text {load }} \\
\text { MVAr }\end{array}$ & 22 & 76 & 36.26 & 15 & 13.44 & 25.27 & 1.94 & 34.65 & 66 & 10 & 10 & 17.64 & 0 & 37.05 & 61.44 & 20 & 13.86 & 65.96 & 36.26 & 26 & 0 & 0 & 54 \\
\hline $\begin{array}{l}\Delta P_{\Sigma} \\
M W\end{array}$ & \multicolumn{23}{|c|}{62.47} \\
\hline $\begin{array}{l}\Delta Q_{\Sigma} \\
\text { MVar }\end{array}$ & \multicolumn{23}{|c|}{422.16} \\
\hline $11-10$ & - & - & - & - & - & - & - & - & - & 0.6 & & - & - & - & - & - & - & - & - & - & - & - & - \\
\hline No. tap & - & - & - & - & - & - & - & - & - & 16 & & - & - & - & - & - & - & - & - & - & - & - & - \\
\hline $12-10$ & - & - & - & - & - & - & - & - & - & \multicolumn{3}{|c|}{0.651} & - & - & - & - & - & - & - & - & - & - & - \\
\hline No. tap & - & - & - & - & - & - & - & - & - & \multicolumn{3}{|c|}{14} & - & - & - & - & - & - & - & - & - & - & - \\
\hline $9-11$ & - & - & - & - & - & - & - & - & \multicolumn{3}{|c|}{0.659} & - & - & - & - & - & - & - & - & - & - & - & - \\
\hline No. tap & - & - & - & - & - & - & - & - & \multicolumn{3}{|c|}{15} & - & - & - & - & - & - & - & - & - & - & - & - \\
\hline $9-12$ & - & - & - & - & - & - & - & - & \multicolumn{4}{|c|}{0.6419} & - & - & - & - & - & - & - & - & - & - & - \\
\hline No. tap & - & - & - & - & - & - & - & - & \multicolumn{4}{|c|}{13} & - & - & - & - & - & - & - & - & - & - & - \\
\hline $7-3$ & - & - & \multicolumn{5}{|c|}{0.65} & - & - & - & - & - & - & - & - & - & - & - & - & - & - & - & - \\
\hline No. tap & - & - & \multicolumn{5}{|c|}{14} & - & - & - & - & - & - & - & - & - & - & - & - & - & - & - & - \\
\hline
\end{tabular}

Parameters of the normal mode after loads change, taking into account the technical stale of transformers 
Table12

Parameters of the optimal mode after loads change, taking into account the technical state of transformers and corrected transformation ratios

\begin{tabular}{|c|c|c|c|c|c|c|c|c|c|c|c|c|c|c|c|c|c|c|c|c|c|c|c|}
\hline \multirow{2}{*}{ P-ters } & \multicolumn{23}{|c|}{ No. of nodes } \\
\hline & 1 & 2 & 3 & 4 & 5 & 6 & 7 & 8 & 9 & 10 & 11 & 12 & 13 & 14 & 15 & 16 & 17 & 18 & 19 & 20 & 21 & 22 & 23 \\
\hline$P_{\text {load }}, \mathrm{MW}$ & 108 & 187.1 & 176.4 & 74 & 68.16 & 12.2 & 19.4 & 169.2 & 275 & 3.1 & 405 & 54.88 & 0 & 184.3 & 304.3 & 100 & 35.64 & 323.0 & 177.3 & 128 & 0 & 0 & 265 \\
\hline$Q_{\text {load }}, \mathrm{MVAr}$ & \begin{tabular}{|l|l|}
22 \\
\end{tabular} & 76 & 36.26 & 15 & 13.44 & 25.27 & 1.94 & 34.65 & 66 & 10 & \begin{tabular}{|l|l|}
10 & 1 \\
\end{tabular} & 17.64 & 0 & 37.05 & 61.44 & 20 & 13.86 & 65.96 & 36.26 & 26 & 0 & 0 & 54 \\
\hline$\Delta P_{\Sigma}, \mathrm{MW}$ & \multicolumn{23}{|c|}{62.46} \\
\hline$\Delta Q_{\Sigma}, \mathrm{MVar}$ & \multicolumn{23}{|c|}{422.28} \\
\hline $11-10$ & - & - & - & - & - & - & - & - & - & 0.6 & & - & - & - & - & - & - & - & - & - & - & - & - \\
\hline No. tap & - & - & - & - & - & - & - & - & - & $1:$ & 5 & - & - & - & - & - & - & - & - & - & - & - & - \\
\hline $12-10$ & - & - & - & - & - & - & - & - & - & \multicolumn{3}{|c|}{0.641} & - & - & - & - & - & - & - & - & - & - & - \\
\hline No. tap & - & - & - & - & - & - & - & - & - & \multicolumn{3}{|c|}{13} & - & - & - & - & - & - & - & - & - & - & - \\
\hline $9-11$ & - & - & - & - & - & - & - & - & \multicolumn{3}{|c|}{0.6753} & - & - & - & - & - & - & - & - & - & - & - & - \\
\hline No. tap & - & - & - & - & - & - & - & - & \multicolumn{3}{|c|}{ 17 } & - & - & - & - & - & - & - & - & - & - & - & - \\
\hline $9-12$ & - & - & - & - & - & - & - & - & \multicolumn{4}{|c|}{0.6492} & - & - & - & - & - & - & - & - & - & - & - \\
\hline No. tap & - & - & - & - & - & - & - & - & \multicolumn{4}{|c|}{14} & - & - & - & - & - & - & - & - & - & - & - \\
\hline $7-3$ & - & - & \multicolumn{5}{|c|}{0.65} & - & - & - & - & - & - & - & - & - & - & - & - & - & - & - & - \\
\hline No. tap & - & - & \multicolumn{5}{|c|}{14} & - & - & - & - & - & - & - & - & - & - & - & - & - & - & - & - \\
\hline
\end{tabular}

The aim of optimal control is provision of minimum system-wide active power losses that is are determined by the expression

$$
\Delta F=\sum_{i=1}^{n} \Delta P_{i} \rightarrow \min
$$

If $\Delta F_{\text {min. }}=\Delta P_{\text {min. }}$ is the minimum value of the efficiency function (active power losses), $\Delta F_{\text {cur }}=\Delta P_{\text {cur }}$. is the current value of the efficiency function (active power losses), $n$ is the total number of branches in the circuit, $k_{\text {mr.min. }}$ is the value of the transformation ratio at which calculated losses of active power are minimal, then the dependence of active power losses change (values of the efficiency function $\left.\Delta F_{\text {cur. }}^{*}=\frac{\Delta F_{\text {cur. }}}{\Delta F_{\text {min. }}}\right)$ in relative units on the values of transformation ratios $k^{*}=\frac{k_{c u r} \text {. }}{k_{t r \text { min. }}}$ (Fig. 4) for various transformers will
be built.

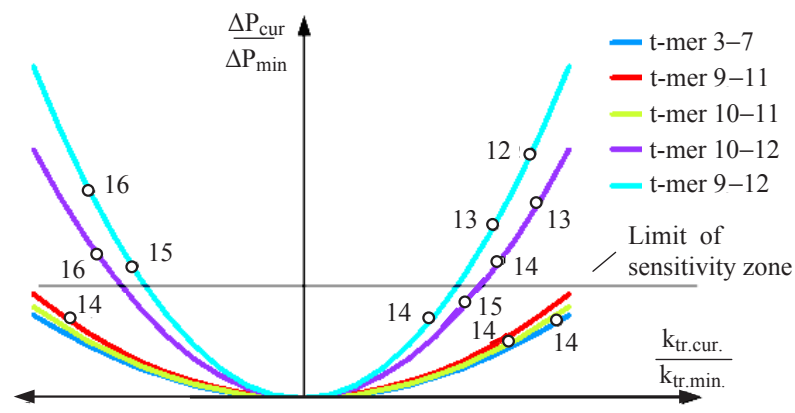

Fig. 4. Charts of dependencies of changes in active power losses on the values of transformation ratios for the small loads mode

Thus, it is possible to perform the transition from the current to the optimal mode by switching the LTC transformer, installed in the branch 9-12 from 13 tap to 14tap and regulation of the transformer in branch $12-10$, by changing the LTC position from tap 14 to 15 tap.

As a result of realization of control actions, the optimal mode will be reached by transformer switching of the branch 11-10 from 14 to 16 tap of LTC, transformer of the branch 12-10 from 15 tap to 14 tap, transformer of the branch 9-11 transformer from 14 to 15 tap and transformer of the branch 9-12 from 14 to 13 tap of LTC, respectively.

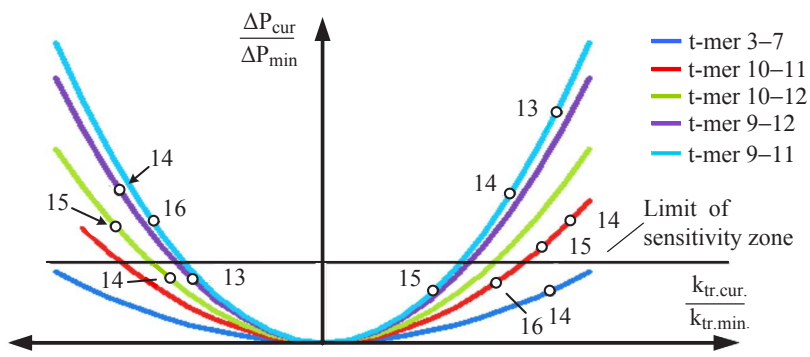

Fig. 5. Charts of dependencies of changes in active power losses on the values of transformation ratios for the large loads mode, without taking into account the technical state of the transformers

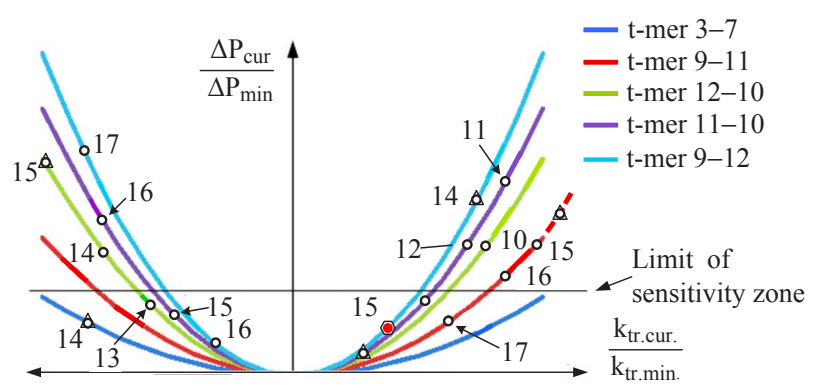

Fig. 6. Optimal transformation ratios for the large loads mode, taking into account the technical state of the transformers

We see that due to consideration of the technical state of transformers, their ranking occurred by the measure of impact on the reduction of active power losses. To reach the optimal mode, now it is more expedient to use a transformer of $9-12$ branch as it reduces most active power losses during one switching of LTC from 14 tap to 15 tap. 


\section{Discussion of the results of determining optimal transformation ratios of EES transformers, taking into account the state of transformers}

The error of RRCT determination by means of the developed mathematical fuzzy model, as compared with the training sample and the opinion of independent experts does not exceed the error of the devices, measuring diagnostic parameters. Such results are explained by complex usage of the probability theory methods, neuro-fuzzy modeling and modern software Matlab.

Such feature of the suggested method for determining the optimal control actions of LTC-transformers, as account of PPCT, in the process of EES modes control, provides such advantages as reduction of the equipment damage rate, decrease of active power losses in the EES. Due to the peculiarities of the method for determining optimal control actions of LTC-transformers, taking into account their technical state, the prospects of developments and introduction of modern microprocessor - based systems of optimal, automatic control of LTC ff transformers to ESS become possible.

As compared with the known method of voltage drop control on the branches of EES circuits [1], with the method of overloads decrease of transmission lines, at the expense of redistribution of power overflows in EES [2], decrease of active power losses in the process of transportation [3] by means of LTC-transformers, the suggested method allows selecting, by means of accounting the suggested RRCT, the transformer for the EES mode control that would simultaneously provide the reduction of power losses and be more reliable.

Usage of quasi-resistances of circuit branches, which, unlike the transformers used, in the process of calculation of nominal resistances of the branches, take into account the transformers state and possible losses of utility companies due to possible damages, allows calculating the EES mode in case of the transformers transformation ratio change and, by means of comparison of calculated power losses, selecting the most efficient transformer.

The suggested peculiarity of application of the method of neuro-fuzzy modeling (usage of the model of the transformer resource in the training sample instead of measured values of diagnostic parameters [12] - coefficients of residual resource, calculated and partially corrected by independent experts) enables to take into account simultaneous impact of the results of both current and periodic control on RRCT.

The drawbacks of the suggested mathematical fuzzy model of RRCT is the necessity of a large data base regarding the coefficient of residual resource of diagnostic parameters CRRDP (Coefficient of residual resource of the diagnostic parameter) for specific transformers. Attempt to reduce the database or use the model of another similar transformer results in the increase of the model error. Limitation on the usage of the RRCT model is the necessity of application only on one - investigated transformer. Therefore, we need models for each transformer. The method of determining optimal control actions by LTC transformers does not take into account voltage limitations in nodes and current limitations in the branches of the circuit.

Further development of the given research will be realized in the development of mathematical models of other types of high voltage equipment, involved in the process of EES modes control, damage of which takes place in our time (Fig. 7)
Problems of the considered research development are caused by the necessity of long lasting experiments and observations over the processes of aging and development of high voltage equipment damage, processes of ESS modes parameters change not only on computer and mathematical models of the equipment and EES modes and on real equipment.
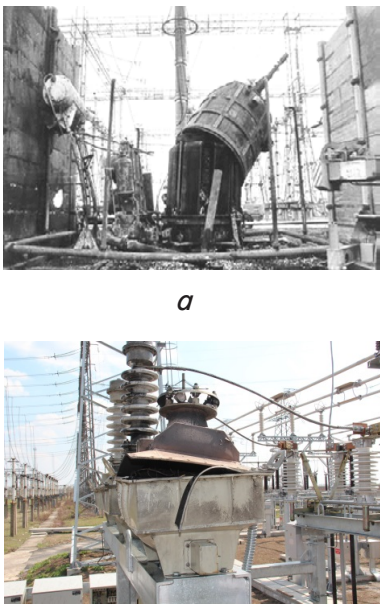

C

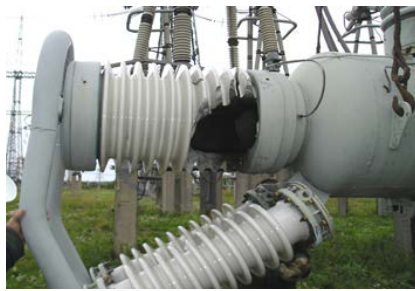

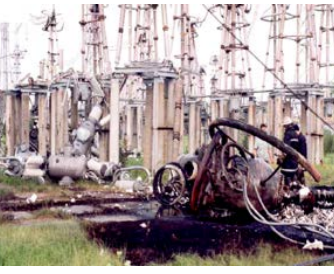
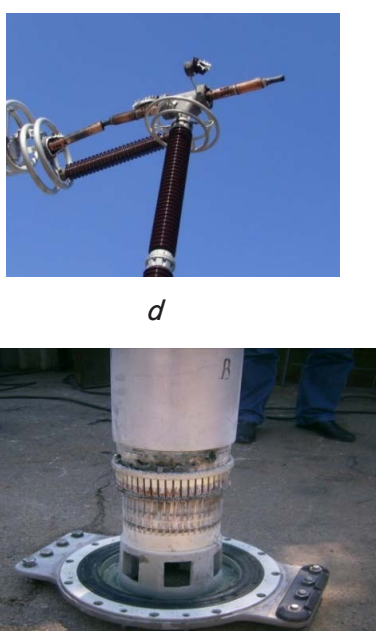

Fig. 7. Damage of high voltage equipment in EES: $a-750 \mathrm{kV}$ shunt reactor; $b$-current transformer and $750 \mathrm{kV}$ air circuit breaker; $c-33 \mathrm{kV}$ voltage transformer; $d-750 \mathrm{kV} \mathrm{SF}_{6}$ circuit breaker; $e-$ air circuit breaker; $f-110 \mathrm{kV} \mathrm{SF}_{6}$ circuit breaker

\section{Conclusions}

1. Analysis of the damage rate of power transformers and methods of the EES modes control suggests that it is necessary to use the results of on-line diagnostics of LTC-transformers not only to determine the expediency of further operation or repair of the equipment, but also for calculation of optimal transformation values (with the account of the suggested RRCT) for their usage in the process of modes control.

2. By means of the usage of the methods of neural-fuzzy modeling, the model of RRCT is developed. The model enables, by means of accounting of both current and retrospective values of diagnostic parameters, to investigate the influence of diagnostic parameters on RRCT and determine its current value. That is necessary for automatic and automated reliable and optimal control of EES modes.

3. The improved method for determining control actions by LTC-transformers, by means of comparative analysis of the results of calculation of EES modes with quasi-resistances of circuit branches, enables to select the transformer and calculate the transformation ratio that provides the minimal number of LTC switching. 


\section{References}

1. Jakushokas, R. Power Network Optimization Based on Link Breaking Methodology [Text] / R. Jakushokas, E. G. Friedman // IEEE Transactions on Very Large Scale Integration (VLSI) Systems. - 2013. - Vol. 21, Issue 5. - P. 983-987. doi: 10.1109/ tvlsi.2012.2201186

2. Reddy, T. Application of Phase Shifting Transformer in Indian Power System [Text] / T. Reddy, A. Gulati, M. I. Khan, R. Koul // International Journal of Computer and Electrical Engineering. - 2012. - Vol. 4, Issue 2. - P. 242-245. doi: 10.7763/ijcee.2012.v4.487

3. Kolcun, M. Transformer use for active power flow control in the electric power system [Text] / M. Kolcun, D. Hluben, L. Bena, N. Djagarov, Z. Grozdev // 2010 9th International Conference on Environment and Electrical Engineering. - 2010. doi: 10.1109/ eeeic.2010.5489982

4. Bocovich, M. Overview of series connected flexible AC transmission systems (FACTS) [Text] / M. Bocovich, K. Iyer, R. M. Terhaar, N. Mohan // 2013 North American Power Symposium (NAPS). - 2013. doi: 10.1109/naps.2013.6666915

5. Constantin, C. Power flow control solutions in the Romanian power system under high wind generation conditions [Text] / C. Constantin, M. Eremia, L. Toma // 2013 IEEE Grenoble Conference. - 2013. doi: 10.1109/ptc.2013.6652353

6. Alekseev, B. A. Large power transformers: state control in the process of operation and revision [Text] / B. A. Alekseev. - Moscow: NTF «Energoprogress», 2010. -88 p.

7. Rassalsky, A. M. Integrated approach to the diagnostics of high-voltage substation equipment $220-1150 \mathrm{~kW}$ under operating voltage in operation conditions [Text] / A. M. Rassalsky, A. A. Sahno, S. P. Konogray, A. A. Hooke // Electric engineering and electro mechanics. - 2010. - Vol. 4. - P. 23-25.

8. Stohniy, B. S. Osnovy monitorynhu v elektroenerhetytsi. Pro poniattia monitorynhu [Text] / B. S. Stohniy, M. F. Sopel // Tekhnichna elektrodynamika. - 2013. - Issue 1. - P. 62-69.

9. Stohniy, B. S. Zastosuvannia zasobiv monitorynhu perekhidnykh rezhymiv v OES Ukrainy pry rozviazanni zadach dyspetcherskoho keruvannia [Text] / B. S. Stohniy, O. V. Kyrylenko, O. F. Butkevych, M. F. Sopel // Pratsi Instytutu elektrodynamiky Natsionalnoi akademiy nauk Ukrainy. - 2009. - Issue 23. - P. 147-155.

10. Buslavets, O. Evaluation and increase of load capacity of on-load tap changing transformers for improvement of their regulating possibilities [Text] / O. Buslavets, P. Lezhniuk, O. Rubanenko // Eastern-European Journal of Enterprise Technologies. - 2015. Vol. 2, Issue 8 (74). - P. 35-41. doi: 10.15587/1729-4061.2015.39881

11. Kylymchuk, A. B. Reduction of Additional Losses of Electric Energy in Parallel Operating Non-Uniform Electrical Grids Taking into Account Non-Uniformity and Sensitivity [Text] / A. B. Kylymchuk, P. B. Lezhnyuk, O. E. Rubanenko // International Journal of Energy Policy and Management. - 2015. - Vol. 1, Issue 1. - P. 1-5.

12. Lezhniuk, P. D. Operatyvne diahnostuvannia vysokovoltnoho obladnannia v zadachakh optymalnoho keruvannia rezhymamy elektroenerhetychnykh system [Text] / P. D. Lezhniuk, O. Ye. Rubanenko, O. V. Nikitorovych // Tekhnichna elektrodynamika. 2012. - Issue 3. - P. 35-36.

13. Evdokimov, S. A. Stationary System for Monitoring Technical State of Power Transformer [Text] / S. A. Evdokimov, Yu. N. Kondrashova, O. I. Karandaeva, M. S. Gallyamova // Procedia Engineering. - 2016. - Vol. 150. - P. 18-25. doi: 10.1016/j.proeng.2016.07.270

14. Bhutto, G. M. Controlled Operation of the Islanded Portion of the International Council on Large Electric Systems (CIGRE) Low Voltage Distribution Network [Text] / G. M. Bhutto, C. L. Bak, E. Ali // Energies. - 2017. - Vol. 10, Issue 7. - P. 1021. doi: $10.3390 /$ en10071021

15. Alekseev, B. A. Kontrol' sostoyaniya (diagnostika) krupnyh silovyh transformatorov [Text] / B. A. Alekseev. - Moscow: Izd-vo NC EHNAS, 2002. -216 p.

16. Tenbohlen, S. Zuverlassigke ist bewertung von Leistungs transformatoren: Materials of HS-Symposium [Text] / S. Tenbohlen, F. Vahidi, J. Gebauer et. al. - Universitat Stuttgart, 2012. - P. 1-11. 